Document downloaded from:

http://hdl.handle.net/10251/122230

This paper must be cited as:

Arias Carrascal, KS.; Garcia-Ortiz, A.; Climent Olmedo, MJ.; Corma Canós, A.; Iborra Chornet, S. (2018). Mutual Valorization of 5-Hydroxymethylfurfural and Glycerol into Valuable Diol Monomers with Solid Acid Catalysts. ACS Sustainable Chemistry \& Engineering. 6(3):4239-4245. https://doi.org/10.1021/acssuschemeng.7b04685

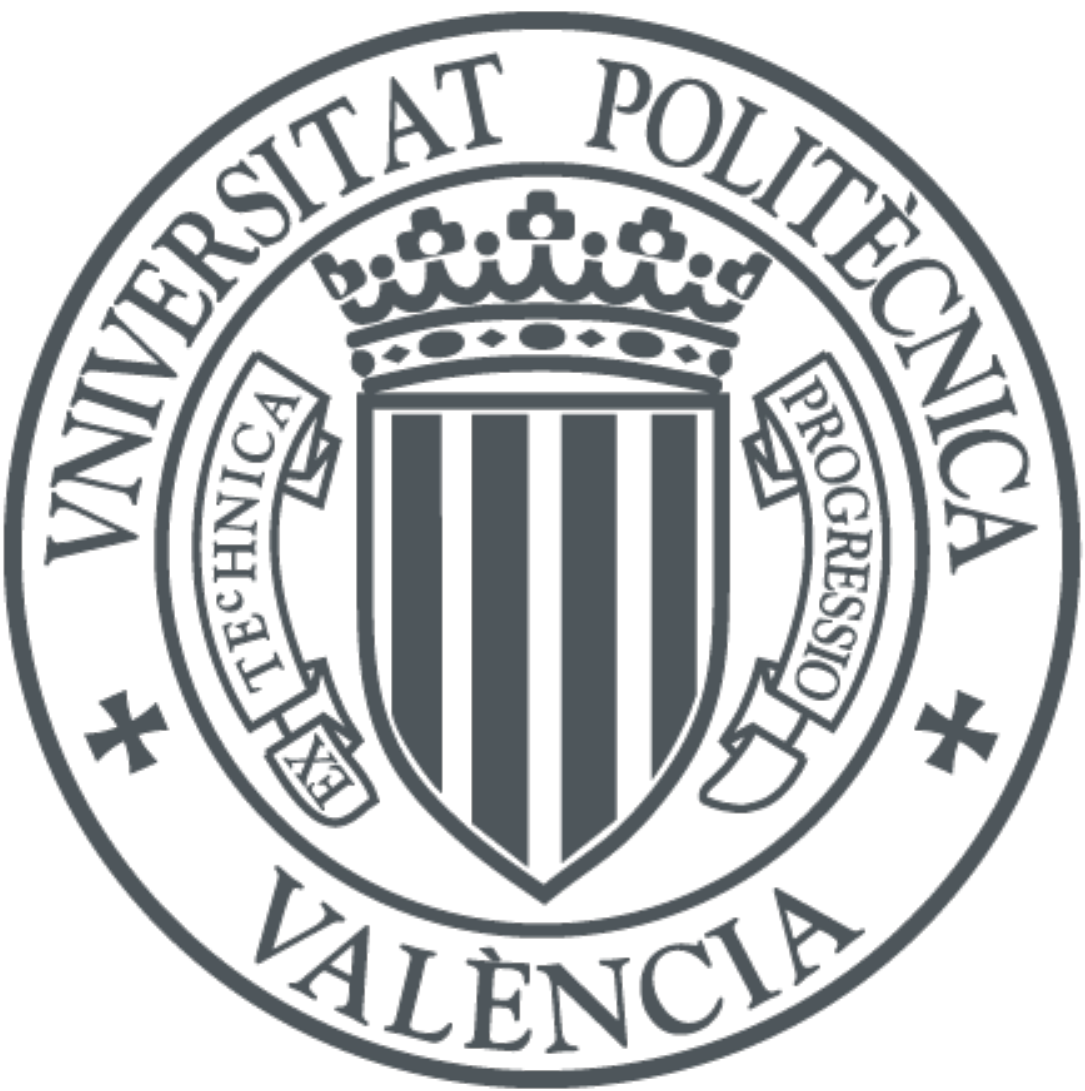

The final publication is available at

https://doi.org/10.1021/acssuschemeng.7b04685

Copyright American Chemical Society

Additional Information 


\title{
Mutual valorization of 5-hydroxymethylfurfural and glycerol into valuable diol monomers with solid acid catalysts
}

\author{
Karen S. Arias, Andrea Garcia-Ortiz, Maria J. Climent, Avelino Corma*, Sara \\ Iborra* \\ Instituto de Tecnología Química (UPV-CSIC). \\ Universitat Politècnica de València \\ Avda dels Tarongers s/n, 46022, Valencia (Spain) \\ Fax: (+34) 963877809 \\ E-mail: acorma@itq.upv.es \\ siborra@itq.upv.es
}

\section{Abstract}

Biomass platform molecules such as glycerol and 5-hydroxymethylfurfural have been valorized into diol monomers by acetalization reaction in the presence of tridirectional large pore zeolites (HY and Beta), a laminar zeolite (ITQ-2) and a mesoporous aluminosilicate (MCM-41) and a conventional homogeneous acid catalyst (p-toluenesulfonic acid). The influence of the solvent polarity, pore structure, hydrophobic character and acidity of the catalyst on the activity and selectivity to HMF glyceryl acetals has been studied. Results showed that while the homogeneous catalyst mainly promotes polymerization reactions, tridirectional zeolites are more active catalysts but less selective and deactivate more rapidly than mesoporous MCM-41 and delaminated 2D zeolites. ITQ-2 and MCM-41 catalysts with smaller confinement effects, easy diffusion, and adequate surface polarity provide high yield (98\%) and selectivity (100\%) to the target compound. These catalysts are stable and allow regeneration and reuse. 
Keywords: 5-hydroxymethylfurfural glyceryl acetals, platform biomass molecules, diol monomers, ITQ-2, MCM-41.

\section{Introduction}

Nowadays the conversion of platform molecules from biomass in liquid fuels and value added chemicals is an active area of research due to the fossil fuel depletion and environmental degradation. ${ }^{1,2}$

Glycerol is a platform molecule which production has increased considerably in the last years due to the biodiesel process. Due to the oversupply and consequently drop in price of glycerol, a variety of catalytic transformations have been explored to obtain higher value added chemicals from glycerol. $3,4,5,6,7$ Besides glycerol, furfural and 5-hydroxymethylfurfural (HMF)(produced by acid dehydration of pentoses and hexoses respectively ${ }^{8,9}$ ) are platform molecules with great potential to produce biobased chemicals and liquid biofuels. $9,10,11,12$

An interesting approach to valorize glycerol is through the acetalization reaction with carbonyl compounds, which gives cyclic acetals with a wide range of applications in pharmaceuticals, ${ }^{13}$ fragrances, ${ }^{14}$ detergents, ${ }^{15}$ and as fuel additives (i.e. solketal). ${ }^{16}$

In the case of carbonyl furanic compounds, an interesting route to valorize HMF and furfural is to combine with glycerol to produce furfural glyceryl acetals that find application as additives of biodiesel to enhance the viscosity and cold-flow properties. ${ }^{17}$ While HMF glyceryl acetals (as well as different derivatives such as its ether, diethers, esters and diesters) can be used as solvents, lubricants, 
anti-freeze, personal care and particularly in the manufacture of biodegradable and photodegradable polymers with high thermal stability $(\mathrm{Tg}) .{ }^{18}$

A wide variety of liquid and solid acids have been reported as catalysts for acetalization of a variety of aldehydes and ketones with glycerol giving the cyclic acetals, 1,3-dioxolanes and 1,3-dioxanes (see Scheme 1), in different ratios depending on experimental conditions and catalyst.7

While the acetalization of glycerol with furfural in the presence of homogeneous and heterogeneous Bronsted or Lewis acid catalysts has been reported in a limited number of works (see Table S1), the acetalization of HMF with glycerol is scarce. Interestingly, the use of homogeneous and heterogeneous acid catalysts (acid resins such as Lewait and IR20) to produce the HMF glyceryl acetals it is claimed in the patent literature, ${ }^{18}$ but examples about the reaction methodology and performance of the different catalysts are not provided. In the open literature, the only example on acetalization of HMF with glycerol has been reported by Mallesham et al. ${ }^{19}$ using $\mathrm{MoO}_{3} / \mathrm{SnO}_{2}$ as heterogeneous catalyst, with a maximum yield of $63 \%$ of cyclic acetals.

At this point, it has to be considered that the selective production of HMF glyceryl acetals is not an easy task. HMF bearing an alcohol and an aldehyde functions, in the presence of acid catalysts, can react with glycerol to give ether and an acetal respectively, along with the possibility of subsequent polymerization reactions. Moreover, in the presence of the water produced during the reaction, the HMF can be hydrolyzed giving levulinic and formic acids. With all the above in mind, it is clear that a catalyst should be designed 
and optimized to avoid the undesired competing reactions, while directing into the formation of the HMF glyceryl acetals.

The interests of the HMF glyceryl acetals particularly for application as monomers for new polymeric materials, ${ }^{20}$ along with the lack of previous studies on the production of these compounds in high yield and selectivity prompted us to study the possibility to optimize structured aluminosilicates as heterogeneous catalysts for the above mentioned reaction. It was clear to us that catalyst parameters such as acidity, confinement, adsorption-desorption and reactant and product diffusion, together with polarity of the solid, would have to be adapted and optimized to achieve high yields of the acetals. ${ }^{21}$ We will show here that this has been possible and yields of $98 \%$ have been achieved.

\section{EXPERIMENTAL}

\section{Catalysts}

HBeta (CP811) and USY (CBV 720) zeolites were purchased from PQ Zeolites B. V. and were calcined at $580{ }^{\circ} \mathrm{C}$ for $3 \mathrm{~h}$ before use. The mesoporous aluminosilicate MCM-41 (Si/Al=15) was prepared according to the literature, ${ }^{22}$ and the 2D zeolite (ITQ-2, Si/Al=15) was prepared by expansion and subsequent exfoliation of the corresponding laminar precursors of the MWW structure. $^{23}$ Beta-F (an H-Beta zeolite that has been synthesized in fluoride aqueous solution to obtain a zeolite with a low concentration of defects and, therefore, high hydrophobicity) was prepared according the literature. ${ }^{24}$ The main physicochemical characteristics of the catalysts are given in Table S2.

\section{Reaction Procedure}


In a typical reaction, the solid catalyst (25 $\mathrm{mg}, 20 \mathrm{wt} \%$ with respect to HMF) was previously activated in situ by heating at $200{ }^{\circ} \mathrm{C}$ under vacuum (1 Torr) for $2 \mathrm{~h}$ in a glass reactor. Then a mixture of HMF $(1 \mathrm{mmol})$, glycerol $(2 \mathrm{mmol})$ and dodecane (internal standard) in $5 \mathrm{~mL}$ of solvent was added and a Dean-Stark instrument was adapted to remove the water formed. The suspension was heated at $83^{\circ} \mathrm{C}$ in a silicon oil bath and magnetic stirring at $1000 \mathrm{rpm}$ (it was checked that at this speed the reaction is not controlled by external diffusion, see SI). During the reaction, samples were taken at regular periods, and analyzed by gas chromatography. After reaction, the catalyst was filtered off and thoroughly washed with ethanol. The products were purified by silica gel column chromatography using a mixture of hexane and ethyl acetate as eluent (5:95v/v) and identified by ${ }^{1} \mathrm{H},{ }^{13} \mathrm{C}$ NMR spectroscopy (see SI) and GC-MS chromatography. In all cases, the products were obtained as a mixture of the five membered ring acetal (1,3-dioxolane), 1,3-dioxolane-4-methanol,2-[5(hydroxymethyl)-2-furanyl] (1a), and six membered ring acetal (1,3-dioxane), 1,3-dioxan-5-ol,2-[5-(hydroxymethyl)-2-furanyl] (1b), each with a $Z$ and $E$ isomer, respectively. In Figure S1, a typical GC chromatogram of the four isomers mixture is presented.

\section{Results and discussion}

Acetalization is an acid catalysed reaction, which occurs when a carbonyl compound reacts with an alcohol. In the acetalization of HMF with glycerol, the process occurs through the nucleophilic attack of a primary hydroxyl group of glycerol to the protonated carbonyl group of HMF forming the hemiacetal, followed by the removal of a water molecule, while forming the corresponding carbocation (see Scheme S1). In a following step the 1,3-dioxolane and 1,3- 
dioxane isomers are formed depending if the secondary hydroxyl or the primary hydroxyl group of glycerol, respectively, attacks to the carbocation (see Scheme S1). It is generally accepted that the acetalization reaction is strongly affected by electronic and steric factors, and the rate determining step is the formation of the carbocation from the protonated hemiacetal. ${ }^{25}$ Thus, to compensate the low rate of hemiacetal formation the reaction media must be sufficiently acidic to promote protonation of the hemiacetal formed, and sufficiently polar to allow stabilization of the cationic intermediate. ${ }^{25}$ In this study we wanted to avoid the use of liquid acids and because the ability of the zeolite to generate and stabilize carbocations, we started with these materials. We certainly, took also into account that these materials as catalysts are highly stable, easy to be reproduced and offer the possibilities to tune acidity, polarity and pore zeolite dimensions and topologies. Because of the above possibilities of zeolites and the requirement of large pores to allow the formation and diffusion of products, we have first selected a large pore $12 \mathrm{R}$ tridimensional zeolite such as a HBeta. This is easily available commercially, and the acid site density and polarity are tunable by direct synthesis. Thus, for starting, the reaction of HMF with glycerol was performed in the presence of a HBeta zeolite with a silicon to aluminum molar ratio of 12 .

The reaction was first performed using a molar ratio HMF:glycerol=1:2, acetonitrile as a solvent at reflux temperature $\left(83^{\circ} \mathrm{C}\right)$ with a Dean-Stark apparatus to remove the water formed. After $8 \mathrm{~h}$ of reaction time $41 \%$ conversion of HMF was reached and a mixture of the cyclic five membered ring $(E+Z)-(2-(5-h y d r o x y m e t h y l-2-f u r f u r y l)-1,3-d i o x o l a n-4-y l)$ (1a) and six membered ring acetals $(E+Z)-(2-(5-h y d r o x y m e t h y l-2-f u r f u r y l)-1,3-d i o x a n-5-o l,(1 b)$ (Scheme 
1) were obtained with a total yield of $27 \%$ (Table 1). We will refer to HMF glyceryl acetals (1) to the mixture containing the four isomers.

As can be observed in Figure S2, the 1,3-dioxolane isomers (1a) are formed at higher initial rate than the 1,3-dioxane isomers (1b), which agrees with precedent results on the acetalization of glycerol with other carbonyl compounds such as benzaldehyde or acetone, in where it was observed that the formation of the dioxolane ring is kinetically favored. ${ }^{26}$ By products coming from to cross etherification between the primary alcohol of glycerol and the hydroxymethyl group of HMF (2) and its corresponding acetals (3a-b) were detected in minor amounts (Scheme 1). Notice that no self-etherification of HMF to give (5,5'-(oxy-bis(methylene)bis-2-furfural, OBMF) nor levulinic acid or glyceryl levulinate were observed under these reaction conditions. Moreover, a blank reaction performed in the absence of catalyst provided no conversion under our reaction conditions.

Results presented in Table 1 showed that the maximum yield of acetals $1(40 \%)$ was achieved within $24 \mathrm{~h}$ and no important improvement in the yield occurs at longer reaction times (30h) (results not showed). The relatively low yields together with the slope of the kinetic curves (Figure S2) indicate that a strong deactivation of the catalyst occurs during the acetalization reaction. This was tested by recycling the catalyst after use and washing with ethanol and conversion dropped from $55 \%$ to $40 \%$. Indeed, when the catalyst was Soxhlet extracted after the reaction a $95 \mathrm{wt} \%$ of the final catalyst correspond to adsorbed glycerol. The extracted catalyst was reused and conversion increased to $47 \%$, which is still below the conversion with the fresh catalyst. These results indicate that catalyst deactivation is not only due to a strong adsorption of 
glycerol but also to products formed during the reaction. One way to decrease the strong adsorption of organic compounds and therefore catalyst deactivation could be by modifying the polarity of the solvent. Therefore, the polarity of the solvent was modified by using mixtures of a highly polar solvent (acetonitrile) and a solvent with low polarity (trifluorotoluene, TFT). The results presented in Table 1 indicate that the initial reaction rate of acetals formation is affected by the polarity of the solvent giving a maximum when using a volume ratio of TFT: acetonitrile $=1$ (entry 3 ), while the selectivity to acetals 1 was considerably increased. For instance when compared at 50-53 \% HMF conversion, the selectivity to acetals (1) obtained with acetonitrile (entry 1 ) is considerably lower than when using the mixture of solvents (entries 3 and 4). This effect on selectivity can be correlated with an increased desorption of reactants and products from the catalyst surface which limits secondary reactions (formation of ether 2) and subsequent reactions of acetals producing acetal-ether (3) (see Scheme 1). Moreover, it can be observed that the polarity of the solvent has a strong effect on catalyst decay. In fact, using the mixture of solvents, around 82 $\%$ conversion of HMF after $24 \mathrm{~h}$ reaction time could be achieved in all cases, while with acetonitrile, the conversion do not surpass $55 \%$ after $24 \mathrm{~h}$. Nevertheless, the kinetic results under conditions of entry 3, (Figure S3) also indicate a catalyst deactivation although it occurs in a lower extension than using acetonitrile alone (Figure S2). To check the cause of deactivation, after reaction the solid was submitted to a solid-liquid extraction with ethanol using a Soxhlet equipment and $21.5 \mathrm{wt} \%$ (respect the amount of catalyst) of organic material was extracted. Analysis of the extract showed that glycerol was the only compound detected, indicating that glycerol is strongly adsorbed and 
competes with HMF for the zeolite adsorption sites. Since, we have seen the importance of the solvent polarity on adsorption and reactivity, one may lucubrate on the influence of varying the catalyst polarity by changing not only the number of charges on the catalysts (Si/Al ratio) but also by modifying the number of defects (internal silanol groups).

Therefore, the polarity of the catalyst was modified by varying the framework Si/Al ratio, in such way that the higher the framework Si/Al ratio the less polar the zeolites will be. Moreover it is known that synthesis of zeolites in fluoride, instead of $\mathrm{OH}^{-}$media, produces samples with a smaller amount of structural defects or internal silanol groups and consequently, with lower polarity. ${ }^{24}$ Therefore preparing zeolite samples in $\mathrm{OH}^{-}$and $\mathrm{F}^{-}$media, we should be able to match the number of framework Al while changing polarity by decreasing the number of internal defects. Following the above, we have prepared samples of HBeta with framework Si/Al ratios of 12, 25, 50 and 100 in fluoride media (BetaF) that were tested for the acetalization reaction. The main characteristic of Beta-F samples are summarized in Table S2. If the acid site density was the only factor controlling the catalyst activity, a decrease of catalytic activity when increasing the framework Si/Al ratio should be observed. On the other hand, it is clear that zeolites polarity, especially in the samples synthesized in $\mathrm{F}^{-}$media should decrease when increasing the Si/Al ratio. Then, when the initial reaction rate of formation of acetals 1 was ploted versus Si/Al ratio (see Figure S4) a maximum of activity occurs at a Si/Al= 50. This value should represent a compromise between the number of active acid sites and the polarity of the sample. Interestingly, the catalyst surface polarity has a strong influence on selectivity, in such way that the less hydrophobic sample of this series (Beta- 
$F(12))($ Table 2) exhibits the highest selectivity to acetals 1 , whereas the more hydrophobic samples produce the acetal-ether (3) as main byproduct. It appears then that a decrease of surface polarity causes an increase of the concentration of the less polar acetals inside of micropores favoring the subsequent etherification reaction, which lead to lower selectivity.

Unfortunately, a strong deactivation of the catalysts is still observed and HMF conversions do not surpass $69 \%$ after prolonging the reaction time for $24 \mathrm{~h}$ (Table 2). These results show that surface polarity has an impact on the initial reaction rate of formation and selectivity to 1 , but a strong deactivation of the catalyst caused by the strong adsorption of organic material and micropores blockage still occurs when using the microporous zeolite. The extraction with Soxhlet of the used catalyst showed that a $19 \mathrm{wt} \%$ of organic material (with respect to the catalyst weight) was retained on the solid and was composed by $40 \mathrm{wt} \%$ of glycerol and $60 \mathrm{wt} \%$ of $\mathrm{HMF}$.

One way to decrease the amount of products formed by consecutive reactions and which may remaining adsorbed within the pores of the zeolites after reaction, will be by increasing the rate of diffusion of products out the pores of the zeolites. To do that, we used a tridirectional large pore zeolite with some larger pore diameter and larger internal cavities than Beta such as faujasite and more specifically a partially dealuminated zeolites, i.e. a USY(12). When the acetalization reaction was carried out in the presence of the USY zeolite under the same reaction conditions, an increase of the catalytic activity (initial reaction rate of formation of acetals) respect to HBeta zeolite was observed: 0.12 and $0.15 \mathrm{molh}^{-1} \mathrm{~g}^{-1}$ respectively (see Table 3 ), which can be attributed to the higher density of Bronsted acid sites calculated by adsorption-desorption of pyridine 
(Table S2), as well as to the pore system in the USY structure, which improves the diffusion of reactant and products increasing the catalytic activity. Moreover, this increased diffusion of the products has a strong effect on the selectivity to acetals 1, achieving $100 \%$ selectivity. However, the shape of the kinetic curve (see Figure S5) indicates that an important deactivation of the catalyst also occurs during reaction with USY, although in lesser extension than in HBeta zeolite. In fact, the used USY zeolite was extracted after reaction with a Soxhlet equipment using ethanol as a solvent, and the analysis of the organic extract showed that it was composed by glycerol $(10.6 \mathrm{wt} \%$ with respect to the amount of catalyst) while in the case of the regular Beta zeolite the amount of glycerol retained on the catalyst was twofold higher (21.5 wt\%) (see Table S3).

Thus, it appears that the strong adsorption of reactants (particularly glycerol) and products on the strong acid sites and a possible micropore blockage of tridirectional HBeta and USY zeolites are responsible for the fast deactivation observed with these catalysts. In fact the micropore volume of the fresh HBeta and USY decrease from 0.183 to $0.123 \mathrm{~cm}^{3} / \mathrm{g}$ after use, and from 0.266 to $0.178 \mathrm{~cm}^{3} / \mathrm{g}$ after use respectively.

Then, it appears that solid catalysts with larger pores and milder acidities (lower confinement) could be more adequate for performing the acetalization of HMF with glycerol. Following this line of thought, we have selected two new catalysts; one with zeolitic acid properties but with a very large accessible structured external surface a 2D (ITQ-2) zeolite, and another catalyst with large reactants accessibility formed by a mesoporous MCM-41 aluminosilicate material. This last material should not present diffusional restrictions to either reactants or 
products, but present milder acidity than the zeolitic materials. The 2D (ITQ-2) zeolite was prepared by delamination of a layered precursor of MCM-22. ${ }^{23}$

When the acetalization reaction between HMF and glycerol was performed in the presence of ITQ-2, it can be seen (Table 3 and Figure 1) that the initial rate of formation of acetals decreases considerably with respect to those obtained with the tridirecctional large pore zeolites as consequence of the lower acidity of ITQ-2 (see Table S2). However, the 2D structure clearly has a strong influence on the rate of catalyst deactivation achieving $98 \%$ yield of acetals 1 with $100 \%$ selectivity in only $3 \mathrm{~h}$ of reaction time.

At this point, we checked again the influence of the solvent polarity on the catalytic activity of ITQ-2 zeolite by using different ratios of acetonitrile:TFT. The results presented in Table S4 show that, as before, maximum activity as well as selectivity are obtained when working with a mixture acetonitrile:TFT of $1: 1(\mathrm{v} / \mathrm{v})$.

To study the deactivation of the ITQ-2 zeolite and the possibility of reuse in subsequent reaction cycles, the catalyst was filtered off and submitted to a solid-liquid extraction (Soxhlet equipment) using ethanol as solvent during $24 \mathrm{~h}$. When the catalyst was used in a second cycle $72 \%$ yield of acetals 1 was achieved after $24 \mathrm{~h}$ reaction time, which is still considerably larger than those obtained with the HBeta zeolite (43\% yield). The XRD analysis of the used ITQ2 (see Figure S6) showed that the crystalline structure of the catalyst is preserved after reaction. Therefore catalyst deactivation should be attributed to strong adsorption of organic material on the catalyst surface. Indeed, the amount of the organic material extracted by Soxhlet after the first cycle was $16.3 \mathrm{wt} \%$ (respect to the amount of catalyst) which was composed of glycerol 
(98\%), and HMF $(2 \%)$, while the TG analysis of the sample after Soxhlet extraction showed that $5 \mathrm{wt} \%$ of organic material remains adsorbed on the catalyst after solid extraction (Table S3). However, the initial catalytic activity of ITQ-2 zeolite could be fully recovered after calcination at $540{ }^{\circ} \mathrm{C}$ in air and used in four consecutive cycles without loss of activity and selectivity (see Figure S7).

When performing the acetalization reaction between HMF and glycerol with the mesoporous aluminosilicate (MCM-41) with milder acidity than ITQ-2 zeolite (Table S2) and large regular pore size of $3.5 \mathrm{~nm}$, results from Table 3 and Figure S8 show that MCM-41 exhibits lower initial reaction rate than ITQ-2, which is attributed to the lower Bronsted acidity of MCM-41. However, as occurred with ITQ-2, the deactivation rate was also lower than the one observed with tridirectional zeolites, being possible to achieve with the MCM-4194\% yield of acetals 1 with $100 \%$ selectivity after 8 h reaction time. To check the possible catalytic role of the silanol groups that are present in a large number in MCM41 , the acetalization reaction was also carried out with a pure silica MCM-41 sample. No conversion was observed in this case. The results indicate that silanol groups are not acid enough to promote the acetalization reaction, and the active acid sites are Bronsted acid sites associated to tetrahedrally coordinated Al.

The catalyst deactivation was checked by recycling the MCM- 41 used after solid-liquid extraction with ethanol. In this case the yield to glyceryl acetals 1 was $60 \%$ after $24 \mathrm{~h}$, which was lower than that obtained with ITQ-2 (72\%), but considerably superior to those obtained with Beta (43\%).The amount of organic material extracted by Soxhlet was similar for the MCM- 41 and ITQ-2 zeolite but the remaining organic on the MCM-41 surface after Soxhlet extraction and 
determined by TG (10.7 wt\%) was twofold higher than for ITQ-2 (see Table S3). This effect could be attributed to the higher concentration of silanols on the MCM-41 sample with respect to ITQ-2 (see Figure S9), which can contribute to adsorb higher amount of polar molecules on the surface affecting to the rate of deactivation. Nevertheless, the catalytic activity and selectivity of the MCM-41 could be recovered by calcination with air at $540^{\circ} \mathrm{C}$, and the catalyst can be reused successfully (see Figure S10).

Finally, for comparison purposes we have tested the acetalization of HMF with glycerol in homogeneous media using p-toluenesulfonic acid (PTSA), a strong Bronsted acid catalyst. After few minutes of reaction, the reaction mixture evolved to dark color. The GC analysis indicates the presence of numerous unidentified byproducts and strong polymerization of the HMF occurs, being the yield of acetals unappreciable.

\section{Scope of the acetalization reaction}

As delaminated ITQ-2 zeolite represent a good compromise between acidity, adsorption properties and reactant accessibility it was selected as catalyst to examine the scope of the acetalization reaction of furan based derivatives, such as furfural, 2-methylfurfural and 5-benzylfurfural, with glycerol (entries 1-3). In all cases, excellent yields and selectivities to the corresponding cyclic acetals were obtained (Table 4). Also good results were obtained when other glycols such as 1,2-ethylenglycol and 1,2-propane diol were used in the acetalization of HMF (entries 4 and 5).

\section{Conclusions}


Here we have showed that a successful solid catalyst for performing the acetalization reaction of HMF with glycerol requires a material with mild Bronsted acid sites, large pores to allow diffusion of reactants and products and with a balance between of number of acid sites and surface polarity. The most important issue of the catalyst for this reaction will be to avoid the polymerization of HMF while still be able to catalize the acetalization reaction.

The results showed that a 2D zeolite (ITQ-2) and a structured mesoporous material MCM-41 fit the catalytic requirements of the process, and allow to carry out the reaction with an excellent selectivity to the target compound. Tridirectional zeolites with stronger acidity (more confinement) and narrower pores for product diffusion are more active catalysts but deactivate much more rapidly and are less selective. The former type of materials can offer new possibilities for processing biomass derived products.

Supporting Information. Methods of characterization of the catalysts, spectroscopic data and GC chromatogram of the products, kinetic curves, XRD patterns and IR spectra of the catalysts, reusability of the catalysts, Tables of the results of characterization of the catalysts and catalytic results

\section{Acknowledgments}

Spanish MICINN Project CTQ-2015-67592-P, and Program Severo Ochoa (SEV-2016-0683) are gratefully acknowledged. AGO thanks Severo Ochoa Program for FPI fellowships.

In SI are included, methods of characterization of catalysts, spectroscopic data, kinetic curves, tables and scheme of the described acetalization mechanism. 


\section{References}

${ }^{1}$ Rodríguez, M. R.; De Ruyck, J.; Díaz, P. R.; Verma, V. K.; Bram, S. An LCA based indicator for evaluation of alternative energy routes. Applied Energy, 2011, 88 (3), 630-635, DOI: 10.1016/j.apenergy.2010.08.013.

2 Climent, M. J.; Corma, A.; Iborra, S. Conversion of biomass platform molecules into fuel additives and liquid hydrocarbon fuels. Green Chem. 2014, 16 (2), 516-547, DOI: 10.1039/C3GC41492B.

${ }^{3}$ Kong, P.S.; Aroua, M. K.; Daud, W. M. A. W. Conversion of crude and pure glycerol into derivatives: a feasibility evaluation. Renew. Sustainable Energy Rev., 2016, 63, 533-555, DOI: 10.1016/j.rser.2016.05.054.

${ }^{4}$ Anitha, M.; Kamarudin, S. K.; Kofli, N. T. The potential of glycerol as a valueadded commodity. Chem. Eng. J., 2016, 295, 119-130, DOI: 10.1016/j.cej.2016.03.012.

${ }^{5}$ Guerrero-Urbaneja, P.; Garcia-Sancho, C.; Moreno-Tost, R.; Merida-Robles, J.; Santamaria-Gonzalez, J.; Jimenez-Lopez, A.; Maireles-Torres, P. Glycerol valorization by etherification to polyglycerols by using metal oxides derived from MgFe hydrotalcites. Applied Catalysis, A: General 2014, 470, 199-207.

${ }^{6}$ Len, C.; Delbecq, F.; Cara C. C.; Ruiz Ramos, E. Continuous Flow Conversion of Glycerol into Chemicals: An Overview. Synthesis 2017,49, A-S.

7 Cornejo, A.; Barrio, I,; Campoy, M.; Lázaro, J.; Navarrete, B. Oxygenated fuel additives from glycerol valorization. Main products pathways and effects on fuel properties and engine performance: A critical review. Renew. Sustain. Energy. Rev. 2017, 79, 1400-1413.

8 Zhou, P.; Zhang, Z. One-pot catalytic conversion of carbohydrates into furfural and 5-hydroxymethylfurfural. Catal. Sci. Technol. 2016, 6 (11), 3694-3712, DOI: 10.1039/C6CY00384B.

9 Van Putten, R.J.; Van der Waaal, J.C.; De Jong E.; Rasrendra C.B.; Heeres H.J.; De Vries, J.G., Hydroxymethylfurfural, a versatile platform chemical made from renewable resources. Chem. Rev., 2013, 113, 1499-1597; DOI: $10.1021 / \mathrm{cr} 300182 \mathrm{k}$. 
10 Li, H.; Riisager, A.; Saravanamurugan, S.; Pandey, A.; Sangwan, R. S.; Yang, S.; Luque, R. Carbon-Increasing Catalytic Strategies for Upgrading Biomass into Energy-Intensive Fuels and Chemicals. ACS Catalysis 2018, 8 (1), 148-187.

${ }^{11}$ Kikhtyanin, O.; Bulanek, R.; Frolich, K.; Cejka, J.; Kubicka, D. Aldol condensation of furfural with acetone over ion-exchanged and impregnated potassium BEA zeolites. J. Mol. Catal. A: Chemical 2016, 424, 358-368.

12 Arias, K. S.; Climent, M. J.; Corma, A.; Iborra, S. Two-Dimensional ITQ-2 Zeolite for Biomass Transformation: Synthesis of Alkyl 5-Benzyl-2-furoates as Intermediates for Fine Chemicals. ACS Sustainable Chem. Eng. 2016, 4 (11), 6152-6159, DOI: 10.1021/acssuschemeng.6b01662.

13 Sari, P.; Razzak, M.; Tucker, I. G. Isotropic Systems of Medium-Chain Mono-and Diglycerides for Solubilization of Lipophilic and Hydrophilic Drugs. Pharm. Dev. technol., 2004, 9 (1), 97-106, DOI: 10.1081/PDT-120027422.

${ }^{14}$ Silva, C. A. C.; Figueiredo, F. C. A.; Rodrigues, R.; Sairre, M. I.; Goncalves, M.; Matos, I.; Fonseca, I. M.; Mandelli, D.; Carvalho, W. A. Enhancing the biodiesel manufacturing process by use of glycerin to produce hyacinth fragrance. Clean Technol. Environ. Pol., 2016, 18(5), 1551-1563.

15 Piasecki, A.; Sokołowski, A.; Burczyk, B.; Kotlewska, U. Synthesis and surface properties of chemodegradable anionic surfactants: Sodium (2-n-alkyl1, 3-dioxan-5-yl) sulfates. J. Amer. Oil Chem. Soc. 1997, 74 (1), 33-37, DOI: 10.1007/s11746-997-0115-z.

${ }^{16}$ Moity, L.; Benazzouz, A.; Molinier, V.; Nardello-Rataj, V.; Elmkaddem, M. K.; De Caro, Thiebaud-Roux, S.; Gerbaud, V.; Marion, P.; Aubry, J. M. Glycerol acetals and ketals as bio-based solvents: positioning in Hansen and COSMORS spaces, volatility and stability towards hydrolysis and autoxidation. Green Chem. 2015, 17 (3), 1779-1792, DOI: 10.1039/C4GC02377C.

17 Wegenhart, B. L.; Liu, S.; Thom, M.; Stanley, D.; Abu-Omar, M. M. Solventfree methods for making acetals derived from glycerol and furfural and their use as a biodiesel fuel component. ACS Catal. 2012, 2 (12), 2524-2530, DOI: $10.1021 / \operatorname{cs} 300562 \mathrm{e}$.

18 Bonsignore, P.V. Acetonide of hydroxymethylfurfural and glycerin. WO2008022287A1, February 21, 2008.

19 Mallesham, B.; Sudarsanam, P.; Raju, G.; Reddy, B. M. Design of highly efficient $\mathrm{Mo}$ and $\mathrm{W}$-promoted $\mathrm{SnO}_{2}$ solid acids for heterogeneous catalysis: 
acetalization of bio-glycerol. Green Chem. 2013, 15 (2), 478-489, DOI: 10.1039/C2GC36152C.

20 Zhang, D.; Dumont, M. J. Advances in polymer precursors and bio-based polymers synthesized from 5-hydroxymethylfurfural. J. Polym. Sci. Part A: Polym. Chem. 2017, 55 (2), 1478-1492, DOI: 10.1002/pola.28527.

${ }^{21}$ Arias, Karen S.; Al-Resayes, Saud I.; Climent, M. J.; Corma, A.; Iborra, S. From biomass to chemicals: synthesis of precursors of biodegradable surfactants from 5-hydroxymethylfurfural, ChemSusChem, 2013, 6, 123-131. DOI: $10.1007 / \mathrm{s} 11244-016-0646-3$.

22 Kresge, C. T.; Leonowicz, M. E.; Roth, W. J.; Vartuli, J. C.; Beck, J. S. Ordered mesoporous molecular sieves synthesized by a liquid-crystal template mechanism. Nature, 1992, 359 (6397), 710-712.

${ }^{23}$ Corma, A.; Fornes, V.; Pergher, S.; Maesen, T. L.; Buglass, J. Delaminated zeolite precursors as selective acidic catalysts. Nature, 1998, 396 (6709), 353356.

${ }^{24}$ Climent, M. J.; Corma, A.; Iborra, S. Synthesis of nonsteroidal drugs with antiinflammatory and analgesic activities with zeolites and mesoporous molecular sieve catalysts. J. Catal. 2005, 233 (2), 308-316, DOI: 10.1016/j.jcat.2005.05.003.

25 Serafim, H.; Fonseca, I. M.; Ramos, A. M.; Vital, J.; Castanheiro, J. E. Valorization of glycerol into fuel additives over zeolites as catalysts. Chem Eng J., 2011, 178, 291-296, DOI: 10.1016/j.cej.2011.10.004

26 Deutsch, J.; Martin, A.; Lieske, H. Investigations on heterogeneously catalysed condensations of glycerol to cyclic acetals. J. Catal. 2007, 245 (2), 428-435, DOI: 10.1016/j.jcat.2006.11.006. 

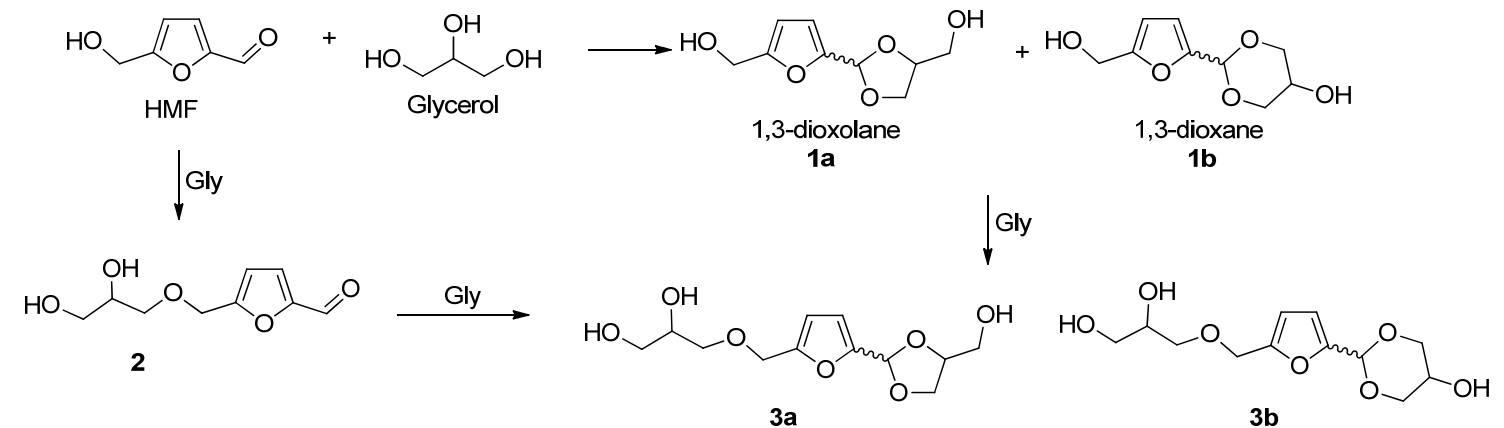

Scheme 1. Pathways for the products formed in the acetalization reaction of HMF with glycerol in the presence of HBeta zeolite. 
Table 1. Results of acetalization of HMF with glycerol in the presence of HBeta zeolite using different mixture of solvents.

\begin{tabular}{|c|c|c|c|c|c|c|c|c|}
\hline Entry & $\begin{array}{c}\text { Solvent } \\
(\mathrm{mL})\end{array}$ & $\begin{array}{c}\mathrm{r}^{\circ} \\
\left(\mathrm{mol} \mathrm{h}^{-1} \mathrm{~g}^{-1}\right)\end{array}$ & $\begin{array}{l}\text { Time } \\
\text { (h) }\end{array}$ & $\begin{array}{c}\text { Conversion } \\
\text { (\%) }\end{array}$ & $\begin{array}{c}\text { Yield (\%) } \\
1\end{array}$ & $\begin{array}{c}\text { Selectivity } \\
\text { (\%) } 1\end{array}$ & $\begin{array}{l}\text { Ratio } \\
\text { 1a/1b }\end{array}$ & $\begin{array}{c}\text { Yield (\%) } \\
2: 3\end{array}$ \\
\hline & (TFT:ACN) & & & & & & & \\
\hline \multirow[t]{3}{*}{1} & $0: 5$ & 0.08 & 2 & 32 & 21 & 66 & 2.0 & $4: 7$ \\
\hline & & & 8 & 41 & 27 & 66 & 2.2 & $8: 7$ \\
\hline & & & 24 & 55 & 40 & 73 & 2.2 & $5: 10$ \\
\hline \multirow[t]{3}{*}{2} & $2: 3$ & 0.09 & 2 & 51 & 39 & 76 & 2.6 & 7:5 \\
\hline & & & 8 & 68 & 51 & 75 & 2.5 & $5: 12$ \\
\hline & & & 24 & 79 & 57 & 72 & 2.4 & $4: 18$ \\
\hline \multirow[t]{3}{*}{3} & $2.5: 2.5$ & 0.12 & 2 & 53 & 51 & 96 & 3.2 & $-: 2$ \\
\hline & & & 8 & 60 & 56 & 93 & 2.8 & $-: 4$ \\
\hline & & & 24 & 82 & 61 & 74 & 2.6 & $-: 21$ \\
\hline \multirow[t]{3}{*}{4} & $3: 2$ & 0.06 & 2 & 51 & 44 & 86 & 3.0 & $2: 5$ \\
\hline & & & 8 & 59 & 45 & 76 & 2.5 & $3: 11$ \\
\hline & & & 24 & 80 & 58 & 73 & 3.0 & $1: 21$ \\
\hline
\end{tabular}

Reaction conditions: HMF (1 mmol), glycerol $(2 \mathrm{mmol}), 20 \mathrm{wt} \%$ of catalyst respect to HMF at $83{ }^{\circ} \mathrm{C}$, Dean-Stark apparatus, $\mathrm{r}^{\circ}\left(\mathrm{mol} \mathrm{h}^{-1} \mathrm{~g}^{-1}\right)$ : initial rate of formation of acetals 1. Further experiments using a higher ratio TFT: ACN could not be performed due to the low solubility of glycerol in the mixture. Mass balance of experiments were $>95 \mathrm{wt} \%$. 
Table 2. Results of the acetalization of HMF with glycerol in the presence of BetaF zeolites samples synthesized in fluoride media (Beta F).

\begin{tabular}{|c|c|c|c|c|c|c|c|}
\hline \multirow[t]{2}{*}{ Catalyst } & $r^{0}$ & Time & Conv (\%) & Yield (\%) & Select.(\%) & Ratio & Yield (\%) \\
\hline & $\mathrm{molh}^{-1} \mathrm{~g}^{-1}$ & (h) & HMF & 1 & 1 & $1 a: 1 b$ & 3: 2 \\
\hline \multirow{3}{*}{ BetaF (12) } & & 0.5 & 23 & 23 & 100 & 3.0 & $-:-$ \\
\hline & 0.28 & 6 & 51 & 50 & 100 & 3.0 & $-:-$ \\
\hline & & 24 & 57 & 56 & 98 & 2.7 & 1:- \\
\hline \multirow{3}{*}{ BetaF (25) } & & 0.5 & 38 & 33 & 87 & 2.6 & 5:- \\
\hline & 0.95 & 6 & 51 & 42 & 82 & 2.4 & $8: 1$ \\
\hline & & 24 & 69 & 57 & 83 & 2.6 & $10: 1$ \\
\hline \multirow{3}{*}{ BetaF (50) } & & 0.5 & 42 & 34 & 81 & 2.6 & 8:- \\
\hline & 1.14 & 6 & 57 & 41 & 73 & 2.4 & $12: 6$ \\
\hline & & 24 & 62 & 45 & 73 & 2.4 & $13: 4$ \\
\hline \multirow{3}{*}{ BetaF (100) } & & 0.5 & 38 & 33 & 87 & 2.6 & 5 \\
\hline & 1.00 & 6 & 51 & 42 & 82 & 2.4 & $8: 1$ \\
\hline & & 24 & 65 & 53 & 82 & 2.4 & $10: 2$ \\
\hline
\end{tabular}


Reaction conditions: HMF (1 mmol), glycerol (2 mmol), TFT:ACN (2.5:2.5 mL), $20 \mathrm{wt} \%$ of catalyst respect HMF, at $83^{\circ} \mathrm{C}$. $\mathrm{r}^{\circ}\left(\mathrm{molh}^{-1} \mathrm{~g}^{-1}\right)$ : initial reaction rate of formation of acetals 1 .

Table 3. Results of acetalization of HMF with glycerol in the presence of different acid catalysts.

\begin{tabular}{|c|c|c|c|c|c|c|c|}
\hline Catalyst & $r^{\circ}$ & Time & Conv. (\%) & Yield (\%) & Select (\%) & Ratio 1a/1b & Yield (\%) \\
\hline (Si/Al) & $\mathrm{molh}^{-1} \mathrm{~g}^{-1}$ & (h) & HMF & 1 & 1 & & 3 \\
\hline HBeta & 0.12 & 2 & 53 & 51 & 96 & 3.2 & 2 \\
\hline \multirow[t]{2}{*}{ (12) } & & 8 & 60 & 56 & 93 & 2.8 & 4 \\
\hline & & 24 & 82 & 61 & 74 & 2.6 & 21 \\
\hline \multirow[t]{3}{*}{ USY(12) } & 0.15 & 2 & 58 & 58 & 100 & 3.5 & - \\
\hline & & 8 & 68 & 68 & 100 & 3.5 & - \\
\hline & & 24 & 75 & 75 & 100 & 3.4 & - \\
\hline \multirow[t]{3}{*}{ ITQ-2(15) } & 0.07 & 0.35 & 50 & 50 & 100 & 2.6 & - \\
\hline & & 1 & 82 & 82 & 100 & 3.2 & - \\
\hline & & 3 & 98 & 98 & 100 & 2.8 & - \\
\hline MCM- & 0.02 & 2 & 58 & 58 & 100 & 4.3 & - \\
\hline \multirow[t]{2}{*}{$41(15)$} & & 8 & 94 & 94 & 100 & 3.9 & - \\
\hline & & 24 & 99 & 99 & 100 & 3.9 & - \\
\hline
\end{tabular}

Reaction conditions: HMF (1 mmol), glycerol $(2 \mathrm{mmol})$, TFT:ACN (2.5 mL:2.5 $\mathrm{mL}), 20 \mathrm{wt} \%$ of catalyst respect $\mathrm{HMF}$, at $83^{\circ} \mathrm{C}, \mathrm{r}^{\circ}\left(\mathrm{molh}^{-1} \mathrm{~g}^{-1}\right)$ : initial rate of formation of acetals 1 . 
Table 4. Synthesis of furan based derived acetals using ITQ-2 (12) zeolite ${ }^{a}$.

\begin{tabular}{|c|c|c|c|c|c|}
\hline Entry & Aldehyde & Alcohol & $\begin{array}{c}\text { Time } \\
\text { (h) }\end{array}$ & $\begin{array}{l}\text { Conv. } \\
(\%)\end{array}$ & Select (\%) \\
\hline \multirow[t]{2}{*}{1} & & & 8 & 90 & 100 \\
\hline & & & 24 & 93 & 100 \\
\hline \multirow[t]{2}{*}{2} & & & 8 & 80 & 100 \\
\hline & & & 24 & 93 & 100 \\
\hline 3 & & & 24 & 78 & 100 \\
\hline $4^{b}$ & & & 24 & 88 & 90 \\
\hline $5^{b}$ & & & 24 & 88 & 94 \\
\hline
\end{tabular}

aReaction conditions: Aldehyde $(1 \mathrm{mmol})$, glycerol $(2 \mathrm{mmol})$, TFT:ACN (2.5 $\mathrm{mL}: 2.5 \mathrm{~mL}$ ) at $83{ }^{\circ} \mathrm{C}$ and Dean-Stark apparatus with $20 \mathrm{wt} \%$ of ITQ-2 respect to the furfural derivative. ${ }^{b} 10 \mathrm{wt} \%$ of ITQ-2 respect to HMF. 


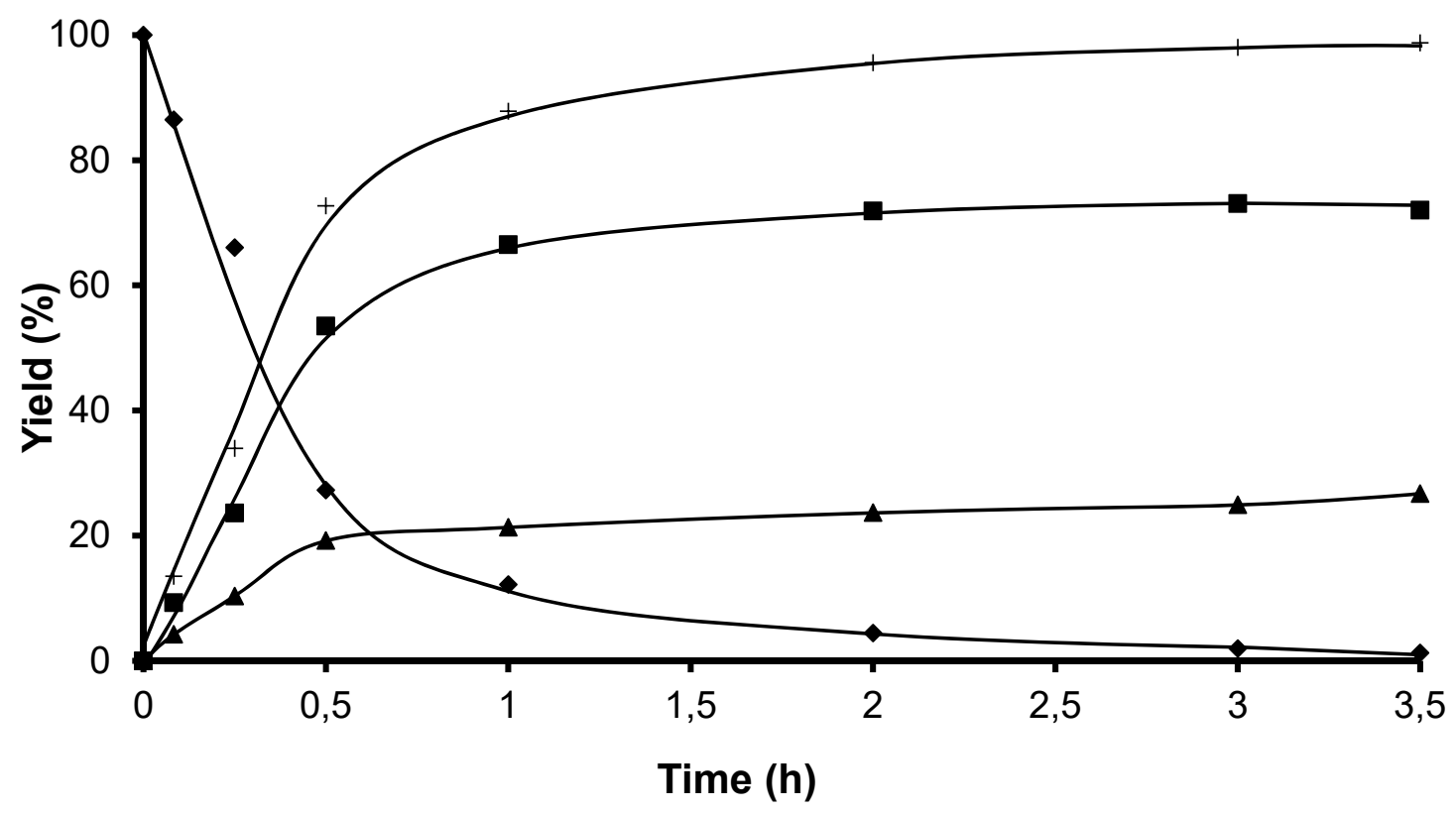

Figure 1. Kinetic curves of the acetalization of HMF (1 mmol) with glycerol (2 $\mathrm{mmol}$ ) in the presence of ITQ-2 zeolite (20 wt\% of catalyst respect to HMF), TFT:ACN $(2.5 \mathrm{~mL}: 2.5 \mathrm{~mL})$ at $83^{\circ} \mathrm{C}$ and Dean-Stark apparatus. $\mathrm{HMF}(\diamond)$, acetal 1a $(\mathbf{\square})$, acetal $\mathbf{1 b}(\Delta)$, acetals $1(+)$. 